\title{
Fas and Fas ligand protein and mRNA in normal and atretic mouse ovarian follicles
}

\author{
S. J. Dharma, R. L. Kelkar and T. D. Nandedkar* \\ National Institute for Research in Reproductive Health, JM Street, Parel, Mumbai-400012, India
}

\begin{abstract}
Apoptosis is the underlying mechanism of follicular atresia in the mammalian ovary. However, the apoptotic pathways governing this ovarian process are not completely elucidated. In the present study, expression of Fas and Fas ligand, the proximal members of the death receptor pathway, was evaluated in mouse ovarian follicles using immunofluorescence and in situ hybridization. Normal or atretic follicles were obtained from immature female
\end{abstract}

Swiss mice after administration of $\mathbf{1 0}$ iu equine chornionic gonadotrophin for 48 or $72 \mathrm{~h}$, respectively. Expression of both Fas and Fas ligand mRNA and protein was observed in granulosa cells of normal and atretic follicles. Although the oocytes of normal follicles failed to show any staining, those of atretic follicles stained intensely for Fas, indicating that the presence of Fas in the oocyte determines the fate of the follicle.

\section{Introduction}

Coordination between oocyte and granulosa cells is an essential prerequisite to normal follicular development. Interactions between granulosa cells through gap junctions and between granulosa cells and oocytes through the microvilli in the zona pellucida have been reported (Canipari, 2000). Studies in rat (Peluso and Pappalardo, 1994; Peluso et al., 1996) and bovine (Luciano et al., 2000) granulosa cells have demonstrated that cell-cell contact plays a vital role in inhibiting granulosa cell apoptosis and regulating proliferation. Hence, a role for gap and tight junctions between granulosa cells and oocytes in preventing granulosa cell apoptosis has been proposed. Moreover, the molecular reprogramming that leads to oocyte maturation is under the regulatory control of signals from the cumulus cells, in response to gonadotrophin stimulation. Therefore, Moor et al. (1998) suggested that the key to oocyte maturation and subsequent embryo viability resides in the follicular compartment rather than the oocyte.

However, studies in mice in vitro have demonstrated that the oocyte promotes proliferation of granulosa cells from preantral and antral follicles (Vanderhyden et al., 1992) and also regulates steroidogenesis through its secretory factors (Vanderhyden and Macdonald, 1998). Hence, the control of ovarian follicular development and function has been attributed to the oocyte (Eppig, 2001; Eppig et al., 2002). Therefore, it appears that oocyte-granulosa cell interaction, finely tuned by factors expressed in both these follicular components, plays

*Correspondence

Email: cellbioirr@hotmail.com a vital role in propelling the follicle either towards ovulation or degeneration (that is, atresia).

Morphological and biochemical studies have shown that the demise of both somatic and germ cells in the ovary is mediated by apoptosis (Hughes and Gorospe, 1991; Morita and Tilly, 1999). Apoptotic changes have been observed in granulosa cells of atretic follicles (Hseuh et al., 1994) and expression of members of the BCl-2 gene family (Tilly et al., 1995; Morita et al., 1999; Nandedkar and Dharma, 2001) and the tumour necrosis factor $\alpha$ receptor (TNF $\alpha-R)$ family have been reported in various species during atresia (Guo et al., 1997; Kim et al., 1998, 1999; Porter et al., 2000) and luteolysis (Roughton et al., 1999). Studies in vitro have demonstrated that apoptosis induced by serum withdrawal in bovine granulosa cells is mediated by the Fas-Fas ligand pathway (Hu et al., 2001). It remains unclear whether the oocyte plays a role in inducingsignalling apoptotic changes in the follicle and whether it expresses any of the known apoptotic factors.

Fas is a cell membrane integral glycoprotein similar to $\mathrm{TNF} \alpha-\mathrm{R}$, whereas Fas ligand (Fas L) is a type II membrane protein homologous to TNF- $\alpha$. Apoptosis is induced in Fas-bearing cells when Fas L binds to Fas, leading to the activation of the Fas-associated death domain (FADD). The death domain, in turn, forms a docking site for the autocatalytic activation of procaspase 8 (Chinnaiyan et al., 1995; Nagata and Goldstein, 1995; Ashkenazi and Dixit, 1999). Once activated, caspase 8 can stimulate other downstream proteases such as caspase 3. These proteolytic effectors of cell death cleave key cellular substrates, thereby disorganizing the cellular assembly and executing apoptosis (Thornberry et al., 1997; Thornberry and Lazebnik, 1998). 
In the present study, the expression of Fas and Fas L mRNA and protein has been studied in oocytes and granulosa cells of normal and atretic ovarian follicles. mRNA expression was studied by in situ hybridization and Fas and Fas $L$ proteins were localized in ovarian follicles and denuded oocytes by immunofluorescence. Expression of Fas protein was compared in granulosa cells isolated from normal and atretic follicles by western blot analysis. Results indicate a possible role for the Fas-Fas L signalling system in oocyte-granulosa cell interaction leading to follicular atresia.

\section{Materials and Methods}

\section{Animals}

Swiss mice bred from the animal colony at the National Institute for Research in Reproductive Health were maintained at constant light (12 h light: $12 \mathrm{~h}$ dark), temperature $\left(24^{\circ} \mathrm{C}\right)$ and humidity $(60 \%)$, and were supplied with food and water ad libitum. The animal requirement for the present study was approved by the Institutional Animal Ethics Committee and experiments were performed in accordance with the guidelines set by the Committee for the Purpose of Control and Supervision of Experiments on Animals, India.

\section{Model for follicular atresia}

Twenty immature female mice aged 21-23 days and weighing 8-10 g were injected s.c. with 10 iu equine chorionic gonadotrophin (eCG) (PMSG; Sigma, St Louis, $\mathrm{MO}$ ) and killed $48 \mathrm{~h}$ later by decapitation (normal group). Animals in a second group were killed $72 \mathrm{~h}$ after eCG administration (atretic group; $n=20$ ). Almost $90 \%$ of follicles in a normal group are antral follicles, and $>90 \%$ of the follicles in an atretic group are atretic (Nandedkar and Balchandran, 1982). For in situ hybridization, ovaries were excised, dehydrated through sequential grades of alcohol, cleared in xylene and embedded in paraffin wax. Sections $(5 \mu \mathrm{m})$ were cut on a microtome and mounted on glass slides treated with aminoethoxy-silane (Sigma). For indirect immunofluorescence, ovarian follicles were punctured with a $26 \mathrm{G}$ needle to release the oocyte-cumulus complex (COC). These COCs were used instead of sections as the monoclonal antibodies for Fas and Fas $L$ failed to label the proteins in ovarian sections. Denuded oocytes were obtained after treating the normal and atretic oocyte-cumulus mass with $1 \%(\mathrm{w} / \mathrm{v})$ hyaluronidase (Sigma) for $5 \mathrm{~min}$. The oocyte-cumulus mass or denuded oocytes were fixed in acetone at $-20^{\circ} \mathrm{C}$ for $10 \mathrm{~min}$, mounted on individual slides coated with poly-L-lysine (Sigma) and air dried.

\section{In situ hybridization}

In situ hybridization of Fas and Fas L mRNA was essentially the same as that described for c-myc mRNA by Nandedkar and Dharma (2001). The cDNA sequences for Fas and Fas $L$ were taken from the published literature (Roughton et al., 1999). These oligoprobes were taillabelled with a digoxigenin oligonucleotide tailing kit (Roche Molecular Biochemicals, Mannheim). In brief, after deparaffinization and digestion with proteinase $\mathrm{K}$ $\left(10 \mu \mathrm{g} \mathrm{ml} \mathrm{m}^{-1}\right.$ at $37^{\circ} \mathrm{C}$ for $\left.30 \mathrm{~min}\right)$, sections were postfixed with $4 \%$ paraformaldehyde. After washing the slides in $0.1 \mathrm{mmol} \mathrm{PBS} \mathrm{I}{ }^{-1}$, prehybridization was carried out at room temperature $\left(25^{\circ} \mathrm{C}\right)$ for $1 \mathrm{~h}$ in prehybridization cocktail. This was followed by overnight hybridization at $42^{\circ} \mathrm{C}$ with digoxigenin-labelled cDNA anti-sense and sense oligoprobes dissolved in the prehybridization mixture at a concentration of $0.5 \mathrm{pmol} \mu \mathrm{l}^{-1}$. After stringent post-hybridization washings with various concentrations of SSC and incubation in Tris buffer ( $\mathrm{pH} \mathrm{7.4)} \mathrm{for} 10 \mathrm{~min}$, the slides were blocked with $2 \%$ $(\mathrm{v} / \mathrm{v})$ normal sheep serum in Tris buffer containing $0.3 \%$ $(\mathrm{v} / \mathrm{v})$ Triton-X100 for $1 \mathrm{~h}$ at room temperature. Sections were incubated overnight in alkaline phosphataseconjugated anti-digoxigenin antibody (1:500 dilution; Roche). On the next day, slides were washed twice in Tris buffer for 5 min each. Colour reaction was carried out by incubating the slides in a mixture of nitro blue tetrazolium (Roche) and 5-bromo 4-chloro 3-indolyl phosphate (Roche) for $20 \mathrm{~min}$ at room temperature in the dark. Levamisole $(0.2 \%, \mathrm{w} / \mathrm{v})$ (Sigma) was added in the colour mixture to block endogenous phosphatases. After a wash in distilled water, slides were mounted in aquamount and viewed. The representative areas were photographed under a bright field microscope. For negative controls, the slides were subjected to an identical procedure using digoxigenin-labelled sense probes.

\section{Immunofluorescence}

Oocyte-cumulus masses or denuded oocytes fixed on poly-L-lysine-coated slides were washed in PBS and the specimens were permeabilized by incubating in $0.01 \%(\mathrm{v} / \mathrm{v})$ Triton-X100 (Sigma) in PBS for $5 \mathrm{~min}$. This was followed by incubation in $3 \%(\mathrm{w} / \mathrm{v})$ non-fat dried milk in PBS for 30 min to block nonspecific binding. Slides were then incubated with primary antibody $(5 \mu \mathrm{g}$ $\mathrm{ml}^{-1}$ of hamster anti-mouse Fas or Fas $\mathrm{L}$ monoclonal antibody; Pharmingen, San Diego, CA) overnight at $4^{\circ} \mathrm{C}$. Negative controls were incubated in $1 \%(\mathrm{v} / \mathrm{v}) \mathrm{SP}_{2} \mathrm{O}$ culture supernatants in PBS instead of primary antibody. After PBS washes, secondary antibody (R-Phycoerythrin conjugated mouse anti-hamster IgG; Pharmingen) was applied at a dilution of 1:1000 in the dark at room temperature for $1 \mathrm{~h}$. Slides were washed in distilled water, air dried, mounted in glycerol and observed under blue 
light (Carl Zeiss, Gottingen). Photographs were taken at $x$ 400 magnification using a 400ASA Kodak colour film.

\section{Protein extraction and western blot analysis for Fas}

Twenty immature (23-day-old) female Swiss mice were administered 10 iu eCG. Animals from one group $(n=10)$ were killed $48 \mathrm{~h}$ later to provide normal ovaries and others $(n=10)$ were killed $72 \mathrm{~h}$ later for atretic ovaries. Freshly excised ovaries were teased in ice-cold phosphate buffered saline (PBS, pH 7.4) to extract granulosa cells. The cell suspension was centrifuged at $1000 \mathrm{~g}$ for $5 \mathrm{~min}$. The granulosa cell pellet was suspended in PBS (pH 7.4) containing 1\% SDS $(\mathrm{w} / \mathrm{v})$ and $10 \%$ protease inhibitor cocktail $(\mathrm{w} / \mathrm{v})$. The cell lysate was then sonicated for $2 \mathrm{~min}$ on ice and centrifuged (13000 g, $15 \mathrm{~min})$. Protein content was determined with the Micro-BCA protein assay kit (Pierce Endogen, Rockford, IL). Equal amounts of protein $(30 \mu \mathrm{g})$ from normal and atretic ovaries were resolved on 10\% SDS-PAGE and electrotransferred to nitrocellulose membrane (Bio-Rad Laboratories, Inc). The membrane was blocked with $5 \%$ non-fat dried milk $(\mathrm{w} / \mathrm{v})$ in PBS containing $0.05 \%(\mathrm{v} / \mathrm{v})$ Tween-20. Primary antibody (Fas; Oncogene Research Products, Cambridge, MA) was applied overnight at $4{ }^{\circ} \mathrm{C}$. The membrane was washed three times in PBS ( $\mathrm{pH} 7.4)$ with $0.05 \%$ Tween-20 (v/v) and incubated in horseradish peroxidase-conjugated rabbit antimouse secondary antibody (DAKO, Glostrup) at 1:1000 dilution for $1 \mathrm{~h}$ at room temperature. After three washes in $0.05 \%$ Tween-PBS, bands were visualized using $1 \%$ diaminobenzidine (Sigma) $-0.3 \% \mathrm{H}_{2} \mathrm{O}_{2}$ in PBS.

\section{Results}

In situ hybridization of Fas and Fas $L$ in ovarian follicles

Both Fas (Fig. 1a,b) and Fas L (Fig. 1c,d) were expressed in the granulosa cells of normal (Fig. $1 \mathrm{a}, \mathrm{c}$ ) and atretic follicles (Fig. 1b,d) but expression of Fas was more intense than that of its ligand. However, Fas (Fig. 1b) but not Fas L (Fig. 1d) transcripts were observed in the oocyte of atretic follicles. Oocytes from normal antral follicles did not show any staining for the receptor (Fig. 1a) and its ligand (Fig. 1C). Controls hybridized with the sense strands of Fas (Fig. 1e) and Fas ligand (Fig. 1f) did not show any staining. In both normal and atretic follicles, theca as well as stromal cells failed to show expression of Fas and Fas L.

\section{Expression of Fas and Fas $L$ in the ovarian follicles by immunofluorescence}

Weak or negligible expression for both proteins was observed in the cumulus cells but not oocytes of normal follicles (Fig. 2a,c). In atretic follicles, the cumulus cells expressed both Fas (Fig. 2b) and Fas L (Fig. 2d) but expression of Fas appeared more intense that that of its ligand. However, the atretic oocyte expressed only death receptor Fas (Fig. 2b). Controls processed in the absence of primary antibody did not show any staining (Fig. 2e,f).

\section{Expression of Fas in oocytes isolated from normal and atretic follicles by immunofluorescence}

Localization of Fas protein in oocytes isolated from normal and atretic ovarian follicles after treatment with eCG is shown (Fig. 3). Although the oocyte from the normal follicle did not express the death receptor (Fig. 3a), the oocyte from the atretic follicle stained intensely for Fas protein (Fig. 3b) compared with the atretic oocyte processed as a negative control (Fig. 3C).

\section{Western blot analysis for Fas}

Western blot analysis was carried out with a view to obtain a semi-quantitative estimate of the amount of Fas protein in granulosa cells from normal and atretic follicles. Both normal and atretic granulosa cells expressed the apoptotic protein (observed as a band at $48 \mathrm{kDa}$; Fig. 4). However, expression of Fas was considerably higher in atretic granulosa cells than in the normal cells. Low molecular weight rainbow markers (Bio-Rad Laboratories, Inc.) were resolved simultaneously (Fig. 4, lane 1).

\section{Discussion}

The mouse model used in this study was eCG-induced follicular development and atresia. Normal follicles were observed $48 \mathrm{~h}$ after treatment with eCG, whereas in the absence of hCG, atretic follicles were observed $72 \mathrm{~h}$ after eCG (Nandedkar and Balchandran, 1982). This experimental murine model was based on: (i) the number of normal and atretic follicles; (ii) the number of ova shed in response to hCG (Nandedkar and Balchandran, 1982); (iii) the FSH-binding capacity of granulosa cells (Nandedkar et al., 1985); and (iv) the uptake of FSH (Nandedkar and Balchandran, 1982). Furthermore, the follicular atresia in the present animal model demonstrated apoptotic changes in the granulosa cells as revealed by: (i) DNA fragmentation; (ii) DNA staining by acridine orange (iii) DNA-4,6diamino-2-phenylindole (DAPI) flow cytometric analysis (Nandedkar et al., 1996, 1998); and (iv) TdT-mediated dUTP nick-end labelling (TUNEL)-positive granulosa cells in the atretic follicles (Nandedkar and Dharma, 2001). A similar model for follicular atresia-apoptosis was also reported by Hughes and Gorospe (1991) demonstrating a DNA fragmentation ladder in the granulosa cells of atretic follicles. Thus, substantial evidence 

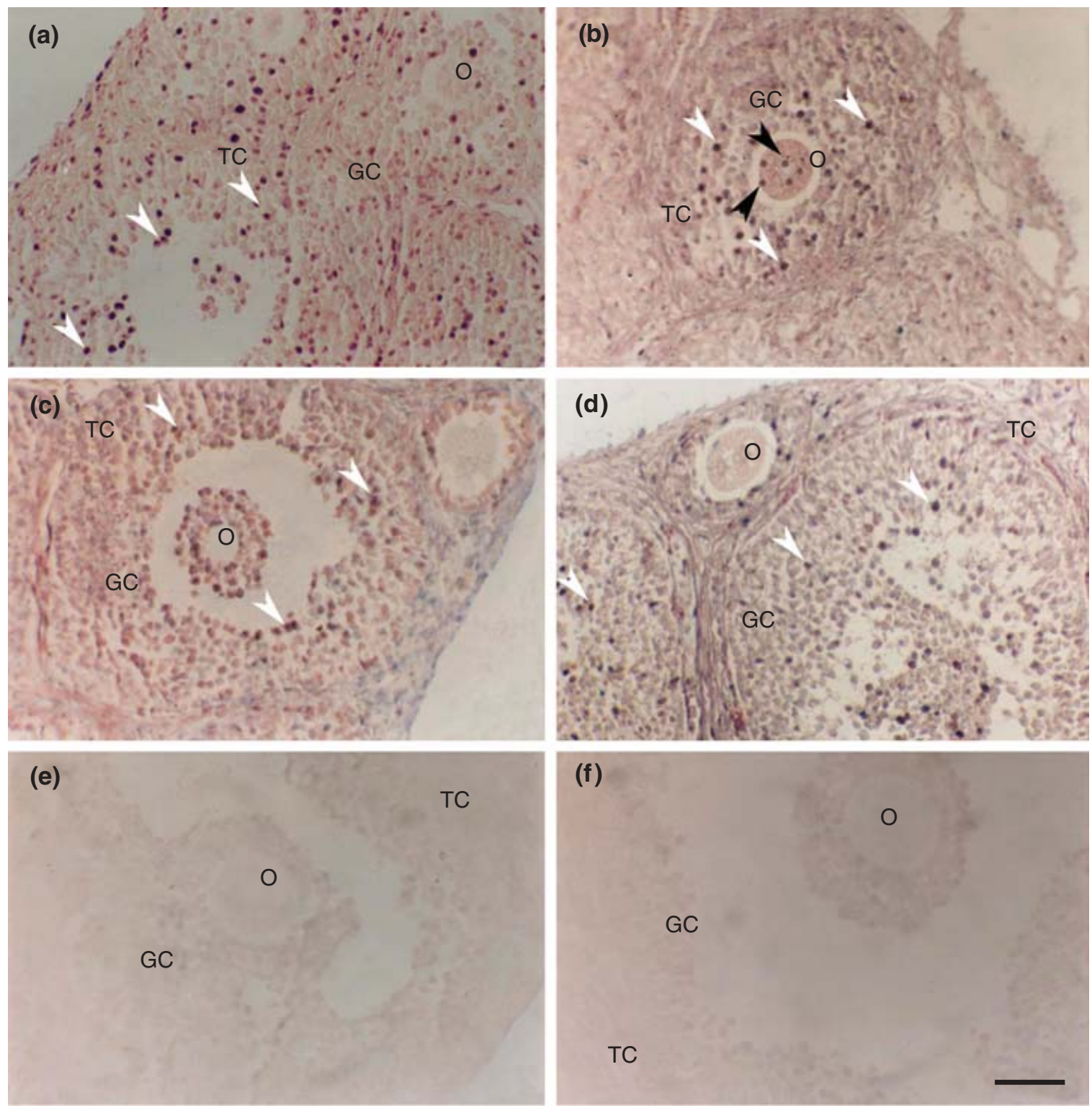

Fig. 1. In situ hybridization analysis of Fas and Fas L mRNA in the normal and atretic mouse ovary. Bright field microscopic images of $(a, c)$ normal and $(b, d)$ atretic ovarian sections hybridized with $(a, b)$ Fas anti-sense and (c,d) Fas L anti-sense oligoprobes. Expression of (a) Fas and (c) Fas L mRNA can be observed in granulosa cells but not oocytes of normal mouse ovarian follicles. Note the expression of (b) Fas and (d) not Fas ligand in atretic follicles. No specific hybridization was observed with the (e) sense Fas and ( $f$ ) Fas ligand cDNA probes. Open and closed arrows indicate staining in the granulosa cells and oocyte, respectively. GC: granulosa cell; O: oocyte; TC: theca cells. Scale bar represents $16 \mu \mathrm{m}$.

has been reported of differentiating normal and atretic follicles in the eCG-induced $48 \mathrm{~h}$ and $72 \mathrm{~h}$ mouse model established by the present authors and used in the present study.

It is well documented that the microenvironment in the follicle is essential in maintaining viability of granulosa cells and oocytes (Moor et al., 1998) and that oocyte-granulosa cell interaction plays an important role in deciding the fate of the follicle (Canipari, 2000;
Eppig, 2001; Eppig et al., 2002). During follicular atresia, apoptosis in the granulosa cells has been reported (Hseuh et al., 1994). One of the major pathways in apoptosis is the Fas-Fas L pathway. Fas $L$ binds to Fas membrane receptor to activate a further cascade of events leading to apoptosis. In the present study, Fas and Fas L proteins and mRNA were expressed in the granulosa cells of normal and atretic follicles. However, Fas protein and mRNA were expressed only on the oocyte of atretic follicles. 

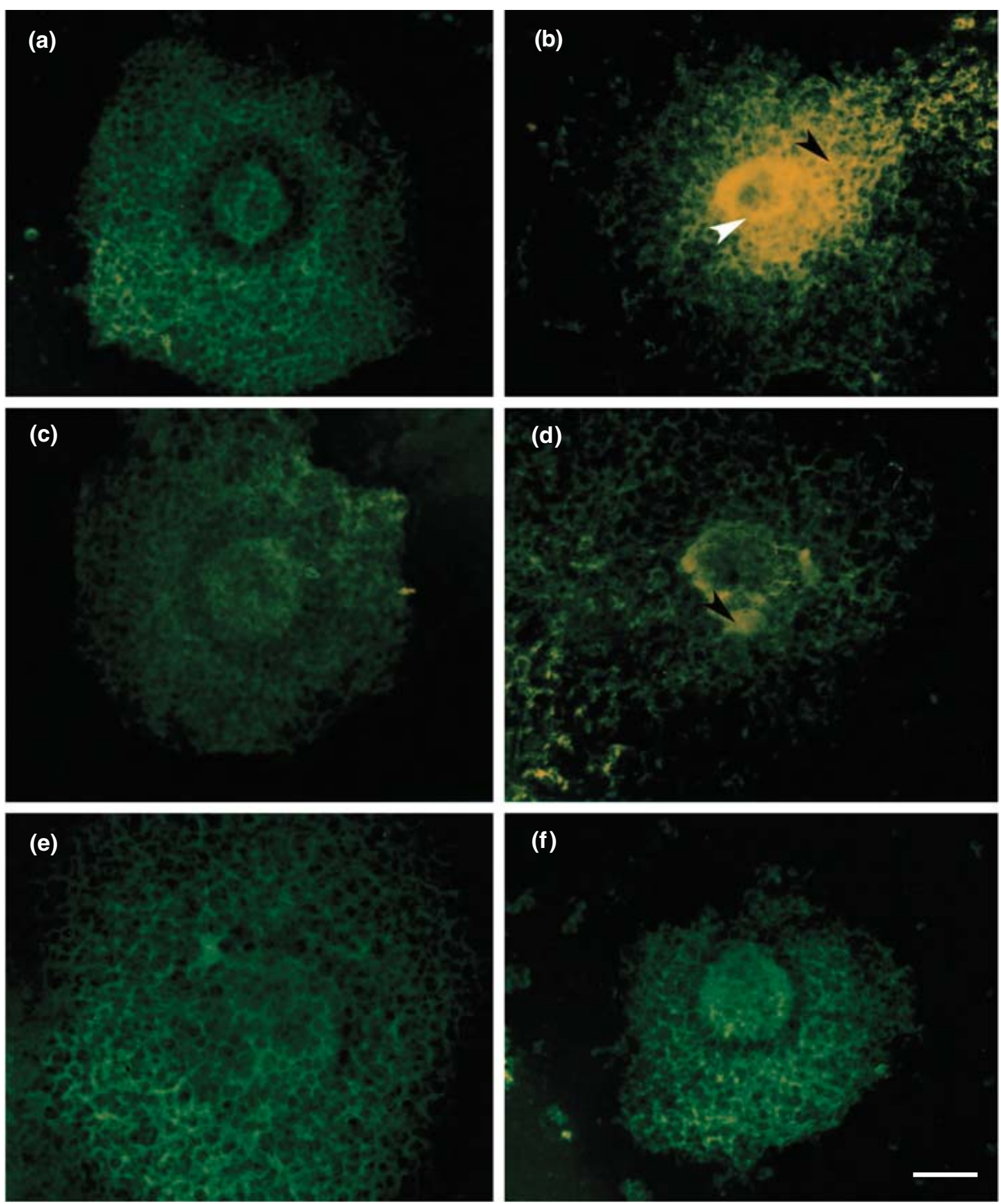

Fig. 2. Localization of Fas and Fas $L$ protein in oocyte cumulus complexes of normal and atretic follicles by immunofluorescence. (b) Intense expression of Fas was observed in the oocyte and granulosa cells of atretic follicle. (d) Expression of Fas L was noted only in granulosa cells. Staining was negligible for Fas and Fas L in $(\mathrm{a}, \mathrm{C})$ normal follicles as well as $(\mathrm{e}, \mathrm{f})$ in negative controls incubated in $\mathrm{SP}_{2} \mathrm{O}$ culture medium. Open and closed arrows indicate staining in oocyte and granulosa cells, respectively. Scale bar represents $16 \mu \mathrm{m}$.

The specific expression of the Fas gene and protein on the atretic oocyte seems to play an important role. The Fas L on the granulosa cells possibly binds to Fas on the oocyte, leading to atresia of the follicle. As Fas $L$ is expressed on normal as well as atretic granulosa cells, the expression of Fas only on the atretic oocyte possibly determines the fate of the follicle, causing follicular atresia. Evidence has been reported of a Fas-mediated signalling pathway 

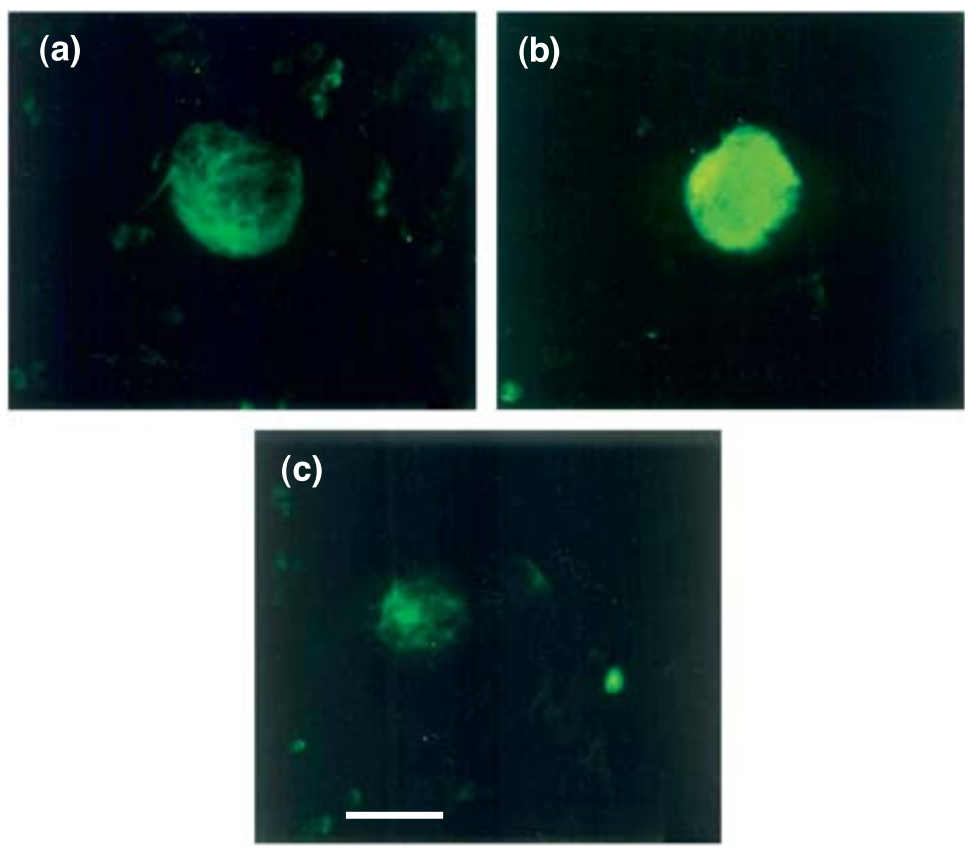

Fig. 3. Expression of Fas protein in denuded oocytes from normal and atretic ovarian follicles by immunofluorescence. (a) Staining was weak in oocytes from normal follicles but (b) intense in atretic oocytes. (c) Immunoreactivity was not observed when $\mathrm{SP}_{2} \mathrm{O}$ culture medium was substituted for primary antibodies. Scale bar represents $16 \mu \mathrm{m}$.

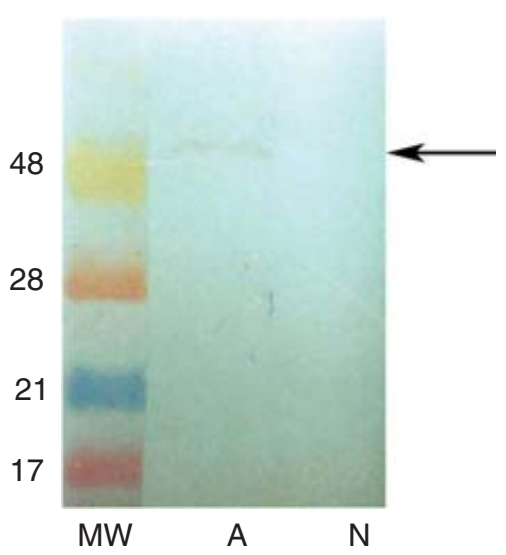

Fig. 4. Western immunoblot analysis of Fas in normal $(\mathrm{N})$ and atretic (A) mouse ovarian follicles. Fas was resolved as a $48 \mathrm{kDa}$ band in the atretic sample. MW: molecular weight markers.

leading to apoptosis in mammalian ovarian granulosa cells (Porter et al., 2000) and luteal cells (Roughton et al., 1999).

The immunolocalization of Fas indicated by immunofluorescence in atretic oocytes could be the result of the presence of Fas in the cumulus cells. Oocytes were denuded and then immunofluorescence for Fas was carried out to verify this hypothesis. The results revealed that the denuded oocytes from atretic but not normal follicles showed localization of Fas, confirming the findings of Porter et al. (2000) and further demonstrating the expression of Fas protein as well as the Fas gene in atretic oocytes, which possibly decide the fate of the follicle.

The authors thank the Director, NIRRH for his support and the Lady Tata Memorial Trust, Mumbai, for financial assistance. The technical help of S. T. Ghanekar and the typing assistance of D. L. D'Souza are acknowledged.

\section{References}

Ashkenazi A and Dixit VM (1999) Apoptosis control by death and decoy receptors Current Opinion in Cell Biology $11255-260$

Canipari R (2000) Oocyte-granulosa cell interactions Human Reproduction Update 6 279-289

Chinnaiyan AM, O'Rourke K, Tewari M and Dixit VM (1995) FADD, a novel death domain containing protein interacts with the death domain of Fas and initiates apoptosis Cell 81 505-512

Eppig JJ (2001) Oocyte control of ovarian follicular development in mammals Reproduction 122 829-839

Eppig JJ, Wigglesworth K and Pendola FL (2002) The mammalian oocyte orchestrates the rate of ovarian follicular development Proceedings National Academy of Sciences USA 99 2890-2894

Guo MW, Xu JP, Mori E, Sato E, Saito S and Mori T (1997) Expression of Fas ligand in murine ovary American Journal of Reproductive Immunology 37 391-398 
Hseuh AJW, Billig H and Tsafiri A (1994) Ovarian follicle atresia: a hormonally controlled apoptotic process Endocrine Reviews 15 707724

Hu CL, Cowan RG, Harman RM, Porter DA and Quirk SM (2001) Apoptosis of bovine granulosa cells after serum withdrawal is mediated by Fas antigen (CD95) and Fas ligand Biology of Reproduction 64 518-526

Hughes FMJ and Gorospe WC (1991) Biochemical identification of apoptosis (programmed cell death) in granulosa cells: evidence for a potential mechanism underlying follicular atresia Endocrinology 129 2415-2422

Kerr JF, Wyllie AH and Currie AR (1972) Apoptosis: a basic biological phenomenon with wide ranging implications in tissue kinetics British Journal of Cancer 26 239-257

Kim JM, Boone DI, Auyeung A and Tsang BK (1998) Granulosa cell apoptosis induced at the penultimate stage of follicular development is associated with increased levels of Fas and Fas ligand in the rat ovary Biology of Reproduction 58 1170-1176

Kim JM, Yoon YD and Tsang BK (1999) Involvement of the Fas/Fas ligand signalling system in p53 mediated granulosa cell apoptosis during follicular development and atresia Endocrinology 140 2307-2317

Luciano AM, Modina S, Gandolfi F, Lauria A and Armstrong DT (2000) Effect of cell-to-cell contact on in vitro deoxyribonucleic acid synthesis and apoptosis responses of bovine granulosa cells to insulin-like growth factor I and epidermal growth factor Biology of Reproduction 63 15801585

Moor RM, Dai Y, Lee C and Fulka J Jr (1998) Oocyte maturation and embryonic failure Human Reproduction Update 4 223-236

Morita Y and Tilly JL (1999) Oocyte apoptosis: like sand through an hour glass Developmental Biology 213 1-17

Morita Y, Perez GI, Maravei DV, Tilly KI and Tilly JL (1999) Targeted expression of $\mathrm{Bcl}-2$ in mouse oocytes inhibits ovarian follicle atresia and prevents spontaneous and chemotherapy-induced oocyte apoptosis in vitro. Molecular Endocrinology 13 841-850

Nagata S and Goldstein P (1995) The Fas death factor Science 2671449 1456

Nandedkar TD and Balachandran PK (1982) PMSG induced follicular atresia in mice Indian Journal of Experimental Biology 20 353-354

Nandedkar TD and Dharma SJ (2001) Expression of bcl-xs and c-myc in atretic follicles of mouse ovary Reproductive Biomedicine 3 221-225

Nandedkar TD, Parkar SG, lyer KS, Mahale SD, Moodbidri SB, Mukhopadyaya RR and Joshi DS (1996) Regulation of follicular maturation by human ovarian follicular fluid peptide Journal of Reproduction and Fertility 50 95-104
Nandedkar TD, Rajadhyaksha MS, Mukhopadhyay RR, Rao SGA and Joshi DS (1998) Apoptosis in granulosa cells induced by intrafollicular peptide Journal of Biosciences 23 271-277

Peluso JJ and Pappalardo A (1994) Progesterone and cell-cell adhesion interact to regulate granulosa cell apoptosis Biochemistry and Cell Biology 72 547-551

Peluso JJ, Pappalardo A and Trolice MP (1996) N-Cadherin-mediated cell contact inhibits granulosa cell apoptosis in a progesterone independent manner Endocrinology 137 1196-1203

Porter DA, Vickers SL, Cowan RG, Huber SC and Quirk SM (2000) Expression and function of Fas antigen vary in bovine granulosa cells during ovarian follicular development and atresia Biology of Reproduction 62 62-66

Roughton SA, Lareu RR, Bittles AH and Dharmarajan AM (1999) Fas and Fas ligand messenger ribonucleic acid and protein expression in the rat corpus luteum during apoptosis mediated luteolysis Biology of Reproduction 60 797-804

Thornberry NA and Lazebnik Y (1998) Caspases: enemies within Science 281 1312-1316

Thornberry NA, Rano TA, Peterson EP et al. (1997) A combinatorial approach defines specificities of members of the caspase family and granzyme B. Functional relationships established for key mediators of apoptosis Journal of Biological Chemistry $27217907-$ 17911

Tilly JL, Tilly KI, Kenton ML and Johnson AL (1995) Expression of members of the $\mathrm{Bcl}-2$ gene family in the immature rat ovary: equine chorionic gonadotropin-mediated inhibition of granulosa cell apoptosis is associated with decreased bax and constitutive bcl2 and bcl- $X_{\text {long }}$ messenger RNA levels Endocrinology 136232 241

Vanderhyden BC and Macdonald EA (1998) Mouse oocytes regulate granulosa cell steroidogenesis throughout follicular development Biology of Reproduction 59 1296-1301

Vanderhyden BC, Telfer EE and Eppig JJ (1992) Mouse oocytes promote proliferation of granulosa cells from preantral and antral follicles in vitro. Biology of Reproduction 46 1196-1204

Received 7 May 2003.

First decision 28 July 2003.

Revised manuscript received 27 August 2003.

Accepted 12 September 2003. 